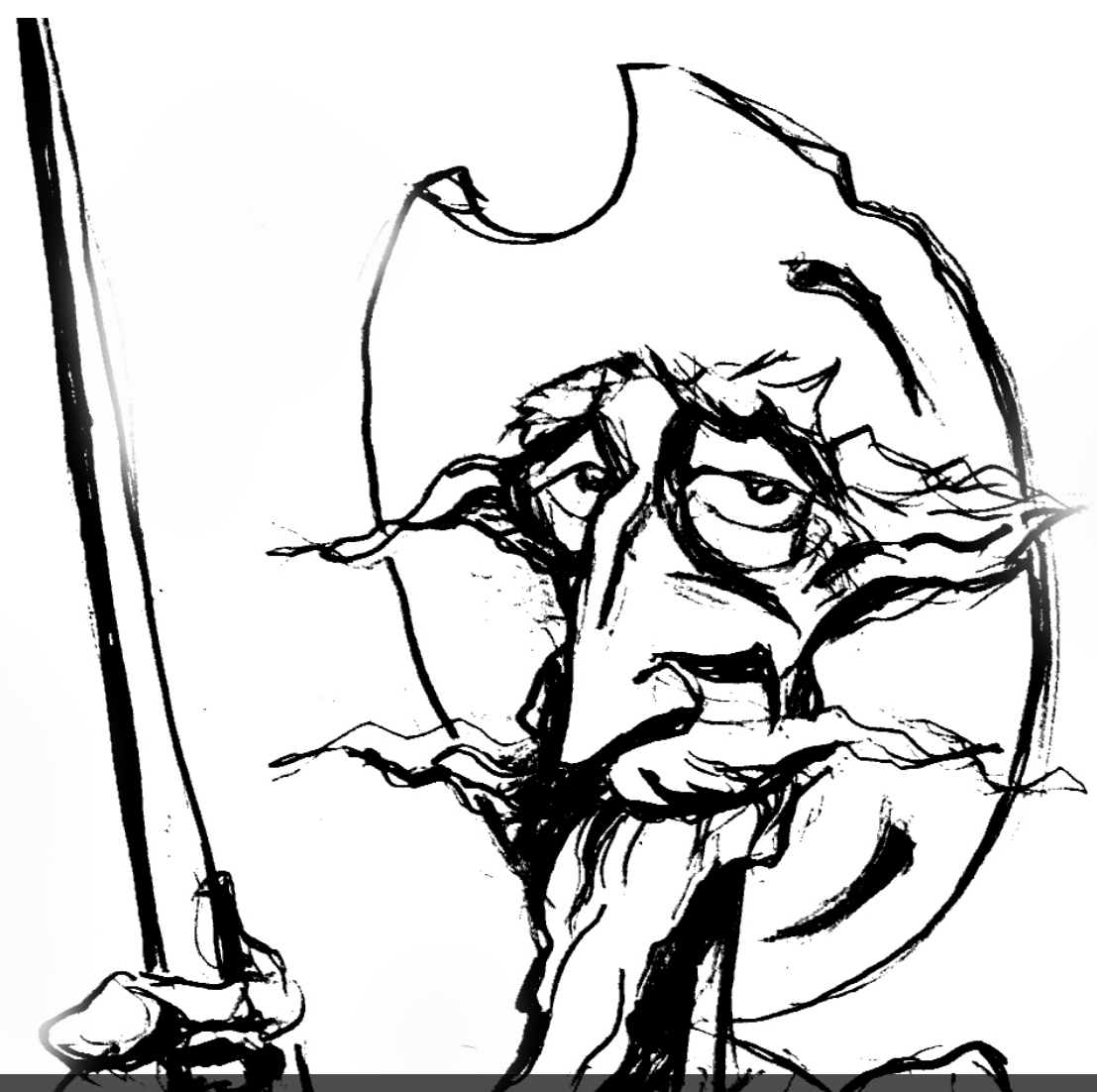

Baje a la Plaza, Señor Presidente: Madres de Plaza de Mayo y Alfonsin frente al proyecto de justicia transicional en Argentina (1983-1985).

[Diego Galante] 


\section{Baje a la Plaza, Señor Presidente: Madres de Plaza de Mayo y Alfonsín frente al proyecto de justicia transicional en Argentina (1983-1985)*}

Get Down to the Plaza, Mr. President: Mothers of the Plaza de Mayo and Alfonsín along Transitional Justice in Argentina (1983-1985)

DiEgo GALANTE

\section{Resumen}

El artículo analiza los posicionamientos, conflictos y debates suscitados entre el gobierno nacional y la Asociación Madres de Plaza de Mayo desde el inicio del período democrático en diciembre de 1983 hasta la sentencia el Juicio a las Juntas Militares en diciembre de 1985. Esas relaciones, forjadas al calor de las iniciativas de dichos actores para el procesamiento de las violaciones a los derechos humanos cometidas dictadura, involucraron distintos momentos de proximidad y ruptura. Se construyeron, a su vez, a partir de dimensiones heterogéneas, que incluyeron claves jurídicas, políticas y culturales.

Palabras clave

Madres de Plaza de Mayo - Alfonsín - derechos humanos - justicia transicional - desaparecidos

\begin{abstract}
The author reviews the debates between Alfonsín's government and Mothers of the Plaza de Mayo organization, from December of 1983 to the end of 1985. Focused on transitional justice policy, such conflicts involved different themes, including legal aspects, political interpretations, and cultural representations about the past of political violence. As this paper shows, that debates involved multiple moments of approach and distance, until a final rupture after the Trial of the Military Juntas.
\end{abstract}

Key words

Mothers of the Plaza de Mayo - Alfonsín - human rights - transitional justice - disappearance of people

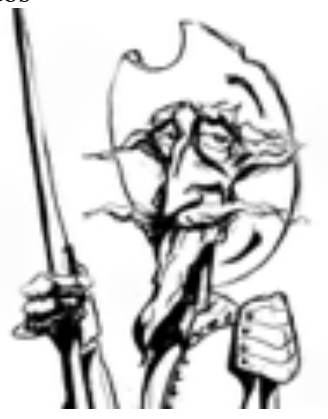

Recibido con pedido de publicación el 10 de diciembre de 2016

Aceptado para su publicación el 15 de marzo de 2017

Versión definitiva recibida el 30 de mayo de 2017

Diego Galante, Instituto de Investigaciones Gino Germani, Universidad Nacional de Buenos Aires, Consejo Nacional de Investigaciones Científicas y Técnicas, Argentina, e-mail: diegalante@ hotmail.com

\footnotetext{
* El autor desea agradecer las observaciones y contribuciones de los evaluadores anónimos de Prohistoria a la versión preliminar de este trabajo.
}

Esta obra se publica bajo licencia Creative Commons. Atribución-NoComercial-CompartirIgual 4.0 Internacional

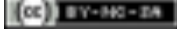

Galante, Diego "Baje a la Plaza, Señor Presidente: Madres de Plaza de Mayo y Alfonsín frente al proyecto de justicia transicional en Argentina (1983-1985)”, Prohistoria, Año XX, núm. 27, jun. 2017, pp. 79-98.

\section{Introducción}

En la transición argentina a la democracia iniciada en 1983, la construcción de conocimiento sobre las violaciones a los derechos humanos perpetradas en dictadura ha sido un proceso gradual y heterogéneo.Ese proceso sostuvo diversas y diferentes etapas, iniciadas todavía en dictadura. Entre ellas, las primeras cartas enviadas en el mismo mes 
del golpe de estado a Videla por los organismos de derechos humanos solicitando esclarecer las desapariciones, la primera ronda de las Madres de Plaza de Mayo en abril de 1977, la visita y el informe de la Comisión Interamericana de Derechos Humanos respectivamente en 1979 y 1980, las exposiciones en el "Coloquio de París" de 1981 que describieron el régimen de desaparición, y la creciente difusión pública en el ocaso del régimen de los crímenes y las desapariciones por parte de los medios de comunicación locales, entre otros procesos que se encadenaron en el plano vernáculo e internacional. En gran parte, aquel conocimiento gradual sobre el sistema de desaparición se construyó acompañando la labor de los organismos de derechos humanos, y en base a una creciente homogeneización en el modo de denunciarlo a partir de las herramientas del género humanitario. ${ }^{1}$

Más allá de la heterogeneidad de origen de los organismos -expresada en sus distintos momentos históricos de conformación, sus áreas y agentes de especialización, y las modalidades predilectas de intervención en la vida pública- las actividades del movimiento de derechos humanos ganaron rápidamente el espacio público a partir de fines de 1982. De manera tal que, tras años de vida política limitada de los partidos, durante la campaña electoral de 1983 y a inicios de la transición "los terribles hechos de la represión del gobierno militar estaban construidos simbólicamente en gran parte de la opinión pública bajo la óptica de la violación a los derechos humanos". ${ }^{2}$ En una medida muy significativa, a partir de sus actividades y protagonismo en el plano local y en el exterior, Madres de Plaza de Mayo fue el símbolo y una de las piezas centrales de esa lucha, a la vez política y basada en la defensa de los derechos fundamentales, que caracterizó al movimiento de derechos humanos durante la transición a la democracia. Entre sus puntos nodales, dichos esfuerzos se condensaron en las demandas para la reconstrucción de una verdad histórica sobre la política de desaparición de personas y la substanciación de procesos de justicia por esos crímenes. ${ }^{3}$

En términos historiográficos, la producción de las ciencias sociales durante los ochenta y noventa se caracterizó por el análisis más general del impacto producido por las acciones, discursos y propuestas del movimiento de derechos humanos en la cultura y el imaginario político colectivo, focalizando con ese fin en los puntos de encuentro que permitían caracterizar globalmente al movimiento. ${ }^{4}$ Investigaciones más recientes se han esforzado por analizar, en cambio, la dinámica intrínseca a las organizaciones, dinámica que permite comprender con mayor profundidad los acuerdos y conflictos que durante los primeros años de democracia incidieron en la definición de la constelación de discursos representativos entre los actores de aquel colectivo. Fundamentalmente,

1 JELIN, Elizabeth "La política de la memoria: el movimiento de derechos humanos y la construcción democrática en la Argentina”, en ACUÑA, Carlos (et al.) Juicio, castigos y memorias: derechos humanos y justicia en la política Argentina, Nueva Visión, Buenos Aires, 1995; CRENZEL, Emilio La historia política del Nunca Más: La memoria de las desapariciones en la Argentina, Siglo XXI, Buenos Aires.

2 LANDI, Oscar y GONZÁLEZ BOMBAL, Inés "Los derechos en la cultura política”, en ACUÑA, Carlos (et al.) Juicio..., cit. p. 157.

3 BRISK, Alison The Politics of Human Rights in Argentina: Protest, Change, and Democratization, Stanford University Press, Stanford, 1994; GORINI, Ulises La rebelión de las Madres, Norma, Buenos Aires, 2006.

4 Aunque la producción es diversa, véase, entre los estudios más representativos, JELIN, Elizabeth (comp.) Los nuevos movimientos sociales, 2 vol., CEAL, Buenos Aires, 1985; y ACUÑA, Carlos (et al.) Juicio ..., cit. 
este último cuerpo de investigaciones permitió vislumbrar la forma en que esos procesos se articularon a partir de una serie de contrapuntos. Por un lado, aquellos entre las sedes regionales y "capitalinas" -luego centrales- de los organismos, cada una de ellas atravesadas lógicas y contextos diferenciados para los procesos políticos, de memoria, y de prosecución de justicia que caracterizaron a la lucha por los derechos humanos en la Argentina de los ochenta. ${ }^{5}$ Por otro lado, a partir de las iniciativas diversas que los distintos organismos adoptaron frente las políticas y medidas promovidas por el gobierno de Alfonsín y la Justicia nacional desde diciembre de 1983, posicionamientos que afectaron la "integración simbólica" del movimiento a la par que fortalecieron a las casas centrales de los organismos como referentes frente a la acción gubernamental. ${ }^{6}$ En el caso de Madres de Plaza de Mayo, ese doble árbol de procesos incidió de manera decisiva en la posterior escisión del organismo entre su Línea Fundadora y la Asociación Madres de Plaza de Mayo a partir de $1986 .{ }^{7}$

Debido a esa amalgama de fenómenos, las relaciones entre los organismos de derechos humanos y la política oficial en los primeros años de la transición a la democracia resultan de vital importancia para comprender las características que asumieron las luchas por la memoria y la justicia en ese período institucional. El gobierno de Raúl Alfonsín, desde su inicio el 10 de diciembre de 1983, apuntó en gran medida a construir su legitimidad y un proyecto de institucionalidad para la transición política a partir de estrategias de elaboración de una "verdad irrestricta" sobre las desapariciones (entendida allí como la construcción de un conocimiento cabal sobre el circuito del régimen de desaparición de personas) y un "tratamiento judicial limitado" para esos crímenes (en términos del número de perpetradores de violaciones a los derechos humanos cuyo juzgamiento se impulsaría). ${ }^{8}$ Estos dos elementos se transformaron en piezas claves e indisociables del programa de justicia ideado para la transición política. Se apuntaba a conformar así, en términos discursivos, una frontera de ruptura con el pasado dictatorial que, a partir de la figura del estado de derecho y su identificación con la idea de democracia, concebía el imperio de la ley como el puntapié inicial para la democratización de otros espacios sociales más amplios. ${ }^{9}$ Los epicentros de esa doble apuesta fueron, por un lado, las actividades de la CONADEP a lo largo de

5 KOTLER, Rubén El país del sí me acuerdo. Los orígenes nacionales y transnacionales del movimiento de derechos humanos en Argentina: De la dictadura a la transición, Editorial Imago Mundi, 2014.

6 ALONSO, Luciano "Las luchas pro derechos humanos en Argentina: de la resistencia antidictatorial a la dispersión del movimiento social”, en Observatorio Latinoamericano, Dossier Argentina: 30 años de democracia, núm. 12, 2013, pp. 104-120.

7 KOTLER, Rubén Los Movimientos Sociales: formas de resistencia a la dictadura. Madres de Detenidos-Desaparecidos de Tucumán, Programa de Historia Oral de la UBA, 2006; SCOCCO, Marianela "De la denuncia a la (in)justicia. Rosario: de la delegación Santa Fe de la CONADEP a los indultos (1983-1990)", Revista Argirópolis, núm. 1, Segundo semestre 2015, pp. 39-60; GORINI, Ulises La otra lucha. Historia de las Madres de Plaza de Mayo Tomo II (1983-1986), Norma, Buenos Aires, 2008.

8 CRENZEL, Emilio "Ideas y estrategias de justicia ante la violencia política y las violaciones a los derechos humanos en la transición política en Argentina (1982-1983)", en FELD, Claudia y FRANCO, Marina (dirs.) Democracia Hora Cero: Actores, políticas y debates en los inicios de la posdictadura, FCE, Buenos Aires, 2015.

9 ABOY CARLÉS, Gerardo Las dos fronteras de la democracia: la reformulación de las identidades políticas de Alfonsín a Menem, Homo Sapiens, Rosario, 2001. 
1984 y el desarrollo ante la Justicia federal del "Juicio a las Juntas Militares" durante 1985.

En buena medida, el programa radical se involucraba así en el campo de los problemas de la justicia transicional, campo que a su vez la experiencia argentina de los ochenta revitalizó como objeto teórico y contribuyó a consolidar. ${ }^{10}$ Por este concepto, suele entenderse el producto de una serie de reflexiones jurídicas, políticas y simbólicas que se plantean por objetivo la recomposición de la estructura jurídica y/o del tejido social, tras situaciones históricas extremas, a partir de procesos de paz, los derechos de las víctimas o los deberes de los estados. Pero también, el conjunto de prácticas y experiencias históricas concretas susceptibles de ser consolidadas y diferenciadas bajo esas características más generales. En esta medida, los procesos de justicia transicional difieren históricamente en función de las características de las formaciones sociales en las que tienen lugar, y se expresan en la participación de diferentes grupos y géneros de actores (sociales, políticos e institucionales) con iniciativas y expectativas crecientes respecto al curso judicial y sus consecuencias políticas esperadas, primando el clima de incertidumbre sobre los resultados finales a alcanzar. ${ }^{11}$

Con el propósito de contribuir a las discusiones previamente citadas, el presente trabajo tiene por objetivo examinar a lo largo de esos dos primeros años de democracia las relaciones, conflictos y desacuerdos públicos producidos entre esos actores -el gobierno nacional y la filial central de Madres de Plaza de Mayo-, cada uno de ellos protagonistas a su modo de esa transición. Como se verá, esas relaciones y disensos se construyeron a partir de dimensiones heterogéneas, que involucraron aspectos jurídicos sobre el alcance de los juzgamientos, evaluaciones políticas distintas sobre la coyuntura y la institucionalidad democrática más amplia, y representaciones culturales diversas sobre los sentidos atribuidos al período de violencia que se evaluaba. ${ }^{12}$

10 TEITEL, Ruti "Transitional justice genealogy", Harvard Human Rigths Journal, vol. 16, 2003, pp. 69-94; ARTHUR, Paige "How 'transitions' reshaped human rights: a conceptual history of transitional justice”, Human Rights Quarterly, vol. 31, núm. 2, 2009, pp. 321-367; SIKKINK, Kathryn The justice cascade: how human rights prosecutions are changing world politics, W. W. Norton \& Company, New York, 2011.

11 ELSTER, Jon Rendición de cuentas: la justicia transicional en perspectiva histórica, Editorial Katz, Buenos Aires, 2006.

12 Metodológicamente, el análisis propuesto se apoya en distintas fuentes secundarias, producciones y documentos oficiales del organismo, del gobierno, parlamentarios y de la Justicia nacional, y el trabajo de archivo sobre diversa producción de prensa del período. En esta medida, cabe advertir que en distintas oportunidades - con aclaraciones de estas fuentes- las expresiones de la presidenta de Madres de Plaza de Mayo, Hebe de Bonafini, son tomadas como la posición oficial del organismo. Ello no implica desconocer la existencia de tensiones por entonces en formación con respecto a la construcción de la enunciación oficial en el organismo (cf. GORINI, Ulises La otra lucha..., cit.). Sin embargo, esta perspectiva metodológica se apoya en el hecho de que, en tanto que presidenta de la organización, a partir de ese rol sus intervenciones eran tomadas por los medios de comunicación de la época como la posición oficial de la organización, y transmitidas de eso modo a la opinión pública más amplia ("Las Madres de Plaza de Mayo solicitaron...", "la presidenta de Madres comunicó que...", etc.) Deseo agradecer a su vez, por su tiempo y su generosidad, a los responsables de los archivos consultados para la realización del presente trabajo: Memoria Abierta (Fondo María del Rosario Cerruti); Centro de Estudios Legales y Sociales; Hemeroteca del Congreso de la Nación Argentina; Biblioteca Asociación Madres de Plaza de Mayo. 


\section{La inauguración del proyecto oficial}

Como es sabido, el proyecto oficial se inauguró a partir de dos decretos emitidos el segundo día hábil de gestión presidencial, los decretos 157 y 158 del 15 de diciembre de 1983, y la consecuente Ley de Reforma del Código de Justicia Militar que el texto de esos decretos anticipaba. ${ }^{13}$ En la práctica, esos instrumentos impulsaron, por un lado, el proyecto formulado durante la campaña electoral para el juzgamiento de las violaciones a los derechos humanos cometidas por los militares durante la dictadura, a partir del discernimiento de tres niveles de responsabilidad entre aquellos "máximos responsables" (en los que se entendía principalmente a los ex comandantes de las Juntas Militares, y cuya prosecución penal se colaba así en el centro de la escena política de la transición), los que se "excedieron" en el cumplimiento de esas órdenes (entre los que se incluía a los perpetradores más emblemáticos en la opinión pública, con distintos grados y rangos al interior de la Fuerzas Armadas), y aquellos otros que acataron esas órdenes bajo "error" -creyendo que eran legítimas- o "coacción". Se proponía, para estos últimos, que debían quedar impunes. ${ }^{14}$ Por otro lado, esos mismos instrumentos, al perseguir al mismo tiempo a los ex comandantes de las Juntas y a los líderes sobrevivientes de las agrupaciones armadas ERP y Montoneros (principales organizaciones políticas de la izquierda revolucionaria argentina de los setenta), inauguraban un itinerario judicial para la llamada "teoría de los dos demonios", nombre con el cual la denuncia del "terrorismo de cualquier signo" comenzó a conocerse en la transición. 15

El trámite parlamentario de la Reforma del Código de Justicia Militar, a lo largo de enero de 1984, habilitó a la Justicia Federal como instancia de alzada para los juicios por los crímenes de militares -tras una primera instancia en el fuero militar, el Consejo Supremo de las Fuerzas Armadas-, e incorporó pequeñas pero sustantivas modificaciones que pusieron en vilo buena parte de las expectativas del gabinete nacional para el tratamiento judicial controlado y limitado de las violaciones a los derechos humanos. ${ }^{16}$ En ese primer debate político público, el radicalismo debió afrontar y responder por primera vez las interpelaciones directas a su proyecto. ${ }^{17}$ Por un lado, afrontó las críticas de sectores políticos allegados a la dictadura militar, como las de la Alianza Autonomista Liberal o el Movimiento Popular Jujeño, cuya diputada María Cristina Guzmán consideró que "hay que recordar a los muertos por la

13 Véase el texto completo de esos decretos y la Ley 23.049 en Boletín Oficial de la República Argentina (BORA), del 15 de diciembre de 1983 y 15 de febrero de 1984. Disponible en internet: www.boletinoficial.gob.ar

14 ACUÑA, Carlos y SMULOVITZ, Catalina "Militares en la transición argentina: del gobierno a la subordinación constitucional”, en ACUÑA, Carlos (et al.) Juicio..., cit.

15 FRANCO, Marina "La 'teoría de los dos demonios' en la primera etapa de la posdictadura", en FELD, Claudia y FRANCO, Marina (dirs.) Democracia ..., cit.

16 Particularmente, al desarticular las distinciones propuestas entre aquellos que se "excedieron" en la represión y los que sencillamente "obedecieron” órdenes. Véase NINO, Carlos Juicio al mal absoluto, Ariel, Buenos Aires, 2006, p. 129.

17 Véase el debate parlamentario de la Ley 23049/84 de Reforma del Código de Justicia Militar [en línea] http://www1.hcdn.gov.ar/dependencias/dip/adebates.htm 
subversión, a las madres de FAMUS, ${ }^{18}$ de la misma manera que a las Madres de Plaza de Mayo". Por otro lado, recibió también los cuestionamientos de los actores más sensibles a las demandas de los organismos de derechos humanos, como el diputado de la Democracia Cristiana Augusto Conte o el Partido Intransigente, pero además gran parte del justicialismo, que comenzó a demandar al gobierno medidas de justicia más severas que las propuestas por el PJ en la campaña electoral. ${ }^{19}$ Finalmente, en esa ocasión, el diputado radical César Jaroslavsky -uno de los principales voceros del Presidente en el Congreso durante el gobierno transicional- debió escuchar el grito de "itraidor!" pronunciado en el recinto por una integrante de Madres de Plaza de Mayo. Ya en diciembre del año anterior, tras conocerse la propuesta de la ley y el impulso al juzgamiento a los ex comandantes, Madres había alertado que se trataba de "un mensaje positivo" pero que había que recordar que "es tan culpable el que asesina como el que manda a asesinar", intervención que habían reforzado también mediante la publicación de una solicitada conjunta con Abuelas de Plaza del Mayo, el CELS, Familiares de Desaparecidos y Detenidos por Razones Políticas y el SERPAJ publicada el 21 de ese mes. ${ }^{20}$

\section{El juego de las diferencias}

Esas intervenciones o alusiones indirectas a Madres como interlocutor real o imaginario de la política oficial de derechos humanos se explican por el hecho de que el proyecto de justicia del gobierno radical se vio acompañado, desde sus comienzos, por una fuerte presencia y difusión en el ámbito público de las actividades de la organización. Desde comienzos de la democracia se produjo una cantidad significativa de producciones periodísticas sobre el organismo, muchas de ellas producidas además en el contexto de la cobertura de prensa de las iniciativas del organismo en el espacio público. Por ejemplo, esa presencia incluyó una entrevista televisiva a Hebe de Bonafini por parte del exitoso ciclo Tiempo Nuevo, conducido entonces por Bernardo Neustadt y Mariano Grondona, y reconocido por ser un recinto de línea editorial "procesista". ${ }^{21}$ La presidenta de la asociación anticipó ya en el programa que la posición de Madres con respecto a la propuesta del gobierno sería intransigente, y que consideraban que el gobierno no cumplió sus compromisos de campaña respecto a los derechos humanos. El

18 Familiares y Amigos de Muertos por la Subversión (FAMUS) es una organización que desde 1983 agrupó activistas con diversos vínculos con instituciones de sociabilidad militar, y cuyas actividades en la transición se orientaron a condenar la persecución penal de militares por las violaciones a los derechos humanos y a promover una "memoria" pública sobre la legitimidad de la "lucha antisubversiva", posiciones construidas en sintonía con los enunciados ideológicos del discurso dictatorial. Véase SALVI, Valentina De vencedores a víctimas: memorias militares sobre el pasado reciente en la Argentina, Biblos, Buenos Aires, 2012.

19 En agosto de 1983, Ítalo Luder, el candidato justicialista, se refirió a los "efectos jurídicos irreversibles" de la autoamnistía que -por entonces un rumor de público conocimiento, luego un hecho- estaban preparando los militares. Si bien Luder moderó esa interpretación en los meses siguientes, la percepción del justicialismo como sector proclive a acatar una transición pactada quedó afianzada en la opinión política. Ver MIGNONE, Emilio Derechos humanos y sociedad: el caso argentino, CELS, Buenos Aires, 1991.

20 Boletín Informativo Madres de Plaza de Mayo, Año II, núm. 1, enero de 1984; El Diario del Juicio del 27/05/1985.

21 La reseña del programa televisivo fue publicada en la revista Flash, una publicación dedicada al mundo de la farándula. En Flash, 14/02/1984. 
programa fue emitido el día 9 de febrero de 1984, a pocos días de sancionarse la Ley de Reforma del Código de Justicia Militar.

También en febrero de 1984 la popular revista Extra publicó fragmentos de un reportaje realizado a la presidenta de la asociación. Bonafini señalaba en esa oportunidad que:

"Las Madres de Plaza de Mayo estamos convencidas de que todas las Fuerzas Armadas están comprometidas en los crímenes cometidos durante la represión. Nosotras reclamamos Justicia, con mayúscula, y lo hacemos porque no queremos violencia. Pero también queremos que sea efectiva y rápida, no como esa justicia a la que estamos acostumbrados los argentinos, que no llega nunca y que cuando llega es muy tarde [...] Por otra parte, la justicia que queremos tendrá que establecer que acá no hubo ninguna guerra [como proponen interpretar los militares], sino un plan siniestro de devastación económica que, para ser aplicado, necesitó del exterminio liso y llano de miles de militantes del campo popular opositores al régimen". ${ }^{22}$

El fragmento, entre muchos otros similares, tiene la facultad de sintetizar cinco grandes núcleos sobre los que se fundamentó la serie de desencuentros entre Madres y el gobierno de Alfonsín en lo que respecta a la política de juzgamientos.

En primer lugar, esas diferencias aludían al problema de a quiénes juzgar y cuál sería el volumen de los procesos judiciales por las violaciones a los derechos humanos cometidas en dictadura. En este marco, durante los primeros dos años de democracia, distintas voces de Madres en múltiples medios de comunicación se ocuparon de subrayar que la pervivencia de la consigna "aparición con vida", fundante de la movilización en dictadura, debía leerse a partir del deber de esclarecer penalmente esos crímenes. Y por lo tanto, en contraposición al "testamento" que entre otros actores el gobierno y la CONADEP impulsaban, según entendían, al sugerir la muerte de los desaparecidos sin acompañar esa afirmación por el debido impulso judicial.

En esta dirección, por ejemplo, las posteriores opiniones de Madres sobre el "Juicio a las Juntas"-el núcleo programático y simbólico de la propuesta oficialresultaron inescindibles de los resquemores del organismo con respecto a que este proceso penal oficiase de vía de clausura para una política judicial más amplia, aquella que involucrase a "todos" los perpetradores directos de las violaciones a los derechos humanos. Así, resulta ilustrativo el paratexto reiterado con el que el periódico del organismo encabezó las diversas notas destinadas a presentar la cobertura de ese proceso penal a lo largo de 1985, a las que titulaba como "el juicio a los 9", en alusión al hecho de que no solo los perpetradores directos se encontraban eximidos de responder por sus crímenes ante el tribunal, sino incluso que no todos los ex comandantes de las Juntas Militares se encontraban sometidos a ese juicio. Esa interpretación y el señalamiento de estas ausencias se encontraban reforzados por las múltiples notas complementarias que en el periódico listaban a los perpetradores identificados y, significativamente, el hecho de que esas nóminas eran reconstruidas en gran medida a partir de los testimonios de las víctimas que recogía el tribunal durante el juicio oral a las Juntas.

22 en Extra, febrero de 1984. 
En segundo lugar, el alcance que según postulaban debía tener la justicia en la transición, además, tenía consecuencias en las consideraciones de Madres sobre cómo investigar los crímenes que quedaban así implicados, y fue uno de los puntos centrales del distanciamiento respecto a las actividades de la Comisión Nacional sobre la Desaparición de Personas, creada por decreto presidencial el 15 de diciembre de 1983 y cuyo célebre informe Nunca Más se conoció nueve meses más tarde..$^{23}$ La demanda para la creación de una comisión investigadora parlamentaria y bicameral, que había encontrado eco en los distintos organismos de defensa de los derechos humanos hacia fines de 1983 y comienzos de 1984, se concebía como la posibilidad más cercana y real de reunir los antecedentes documentales que permitieran, además de un juicio político público que impugnara al régimen militar, su futura condena en los tribunales federales. ${ }^{24}$ La valoración positiva de múltiples actividades de la CONADEP llevaría luego a otros organismos a diluir las demandas en aquella dirección, y se convertiría en uno de los indicadores de la relativa fragmentación de las acciones colectivas del movimiento a partir de entonces. Más en particular, la dirección central de Madres llamó a no concurrir a declarar o a ratificar en esa sede las denuncias ya efectuadas, y si bien algunos grupos de Madres colaboraron con la recolección de la información (como la filial de Mar del Plata o el grupo de Madres de Conscriptos Desaparecidos), el organismo sostuvo públicamente las críticas hacia otros grupos del movimiento de derechos humanos que participaron activamente. ${ }^{25}$ En cambio, sostuvieron la iniciativa para la creación de una comisión bicameral se emplazó también a lo largo de 1984 y 1985.

La construcción de esa distancia respecto a las actividades de la CONADEP se explicaba básicamente por tres motivos. El primero de ellos aludía a la desconfianza respecto a que, en manos del Poder Ejecutivo, la investigación sobre las desapariciones en dictadura verdaderamente resultara en la construcción de un conocimiento sustantivo. El segundo, se basaba en la dubitación sobre las posibilidades de que, la producción eventual de ese conocimiento, tuviera como correlato un impulso a la actuación judicial para el procesamiento de esos crímenes. Los casi nueve mil casos registrados por la CONADEP y el hecho de que las denuncias recogidas fueran presentadas por la Comisión a la Justicia Federal, facilitó que el acervo documental producido en el Nunca Más se convirtiera luego también en un insumo más a partir del cual Madres construía sus denuncias. Sin embargo, una tercera dimensión se comportó como una barrera infranqueable.

Este tercer elemento de ruptura aludía más propiamente a la clave de interpretación cultural para esa violencia represiva que, también durante la campaña electoral pero de manera decisiva a partir de diciembre de 1983, el Poder Ejecutivo y luego el Informe de la CONADEP habían adoptado como contexto explicativo de esa violencia. En este punto, la lectura del pasado que condensaba el discurso de Madres comportaba consecuencias que hacían que su distanciamiento se acrecentara. Estas tenían que ver, particularmente, con el rechazo de la equivalencia que la "teoría de los dos demonios" propiciaba para la impugnación moral de la violencia de estado y las acciones desarrolladas por las organizaciones de la izquierda revolucionaria,

23 CONADEP Nunca más: Informe de la Comisión Nacional sobre la desaparición de personas, EUDEBA, Buenos Aires, 1984.

24 NOVARO, Marcos Argentina en el fin de siglo: Democracia, mercado y nación, Paidós, Buenos Aires, 2009.

25 CRENZEL, Emilio La historia ..., cit., pp. 61-62 y 65. 
valores a partir de los cuales se construía la imagen de la masacre represiva como consecuencia de un enfrentamiento entre esos grupos que arrojó, en una sociedad aterrorizada y externa a esa violencia, un tendal de "víctimas inocentes". ${ }^{26}$ Así, el distanciamiento de Madres con la CONADEP y el gobierno era también un correlato de aquel otro sostenido en base a los discursos sociales que mediaban respecto a las interpretaciones sobre la represión. Particularmente, el pronunciado disenso de Madres con la "teoría de los dos demonios" y el pasivo rol que era atribuido a la sociedad civil en esa clave interpretativa. Cabe destacar, la figura del "pueblo" aparecía en el discurso de Madres como un sujeto oprimido por la dictadura; pero no ya bajo la forma de una sociedad víctima de una violencia indiscriminada, sino la de un colectivo en conflicto frente a la estructuración económica y social promovida por los militares. Ello implicaba postular que muchos sectores de la sociedad argentina fueron consecuentes y se congraciaron con el régimen, entre los que se incluían el sector empresarial, la cúpula sindical tradicional, y la Iglesia Católica. ${ }^{27}$ La presencia de esas interpretaciones había sido relegada en el discurso oficial, pero también, salvo excepciones aisladas, en otros actores del movimiento de derechos humanos.

A partir de allí, en los discursos de Madres -aunque la relación con los desaparecidos se había construido durante la dictadura principalmente a partir de los vínculos sanguíneos y afectivos, elementos que pervivían también en los discursos de la transición ${ }^{28}$ - las víctimas de la represión eran presentadas -en algunas ocasiones en forma explícita y mayormente en forma tácita- como militantes políticos del campo popular, opositores a la dictadura militar, legitimándolos así en el discurso de la democracia que se debía recuperar. A lo largo de las publicaciones del periódico del organismo, esta dimensión se encontró fortalecida en las notas firmadas por colaboradores de la institución, pero también era patente en las editoriales firmadas por Madres de Plaza de Mayo:

"Nuestros hijos eran -cuando fueron secuestrados- militantes
opositores, como lo son hoy miles de argentinos que siguen
combatiendo contra la opresión y la injusticia [...] Lucharon para
impedir que se hambreara al pueblo y se consumara la entrega del país
a través de la implementación de un proyecto económico de

26 En ese marco, la ruptura con las dimensiones simbólicas del Nunca Más resultó irrecuperable. Tras presentarse el Informe en septiembre de 1984, cuyo prólogo incorporaba esas lecturas, el apelativo a la CONADEP bajo el nombre de "Comisión Sábato" (por alusión al escritor que fue su presidente, y en el imaginario público el autor de ese prólogo) se volvió frecuente en las voces de la institución. Esta polémica incorporó una serie de cartas y sus respectivas réplicas entre Ernesto Sábato y Osvaldo Bayer (prestigioso intelectual muy próximo al organismo) que fueron publicadas en el Periódico Madres de Plaza de Mayo; y, posteriormente, la denuncia de esas interpretaciones se hizo traslativa a otros productos culturales que hicieron eco de aquellas memorias, tal como el premiado film $\mathrm{La}$ Historia Oficial de Luis Puenzo, o incluso (aunque poniendo de manifiesto la "antijuricidad" del plan represivo adoptado por las Juntas) la sentencia de la Cámara Federal en el proceso penal a los ex comandantes. Véase el Periódico Madres de Plaza de Mayo núm. 2, 4, 6 y 14, de enero, marzo, y mayo de 1985 y enero de 1986. Sobre la importancia de la figura de la "víctima inocente" en el Informe de la CONADEP y en el clima de época, CRENZEL, Emilio La historia..., cit.

27 Ver, entre otros, Periódico Madres de Plaza de Mayo núm. 2, 6 y 7, de enero, mayo y junio de 1985. FILC, Judith Entre el parentesco y la política, familia y dictadura. 1976-1983, Biblos, Buenos Aires, 1997; JELIN, Elizabeth "¿Víctimas, familiares o ciudadanos/as? Las luchas por la legitimidad de la palabra", en CRENZEL, Emilio (coord.) Los desaparecidos en la Argentina: memorias, representaciones e ideas, Biblos, Buenos Aires, 2010. 
explotación y miseria diseñado por las multinacionales [...] Aún hoy la mayoría de los medios de comunicación hablan de la 'lucha contra la subversión' [...] ¿Quiénes son los terroristas, nuestros hijos o los que los hicieron desaparecer para poder saquear el país?". 29

Cabe aclarar, esta perspectiva no coincidía con una reivindicación política de la lucha armada de los setenta o la homogeneización de los desaparecidos con esa forma de intervención política. En este punto -como también en otros organismos especializados como el CELS, y aunque mediados por aquella lectura de las "dos violencias" en los argumentos del discurso oficial y posteriormente en el discurso de la Cámara Federal- los argumentos de Madres retomaban las claves centrales del discurso jurídico democrático para demostrar que ninguna consideración sobre las responsabilidades políticas de otros actores, en este caso la guerrilla, podía anteceder a los marcos normativos del derecho:

“-¿Usted qué piensa de quienes dirigieron las organizaciones guerrilleras? [...]

“- $[. .$.$] Ya hemos dicho que todo aquél que tenga cuentas pendientes$ con la Justicia, todo aquel que ha violado la ley debe pagar por ello [...] Que se los enjuicie; y si se los encuentra culpables, que reciban la pena correspondiente. Eso vale para ellos y también hubiera valido para nuestros hijos si les hubieran dado oportunidad. Si ellos habían hecho algo ilegal, tendrían que haberlos juzgado. ${ }^{30}$

El 1 de marzo de 1984 lo comunicarían de la siguiente forma tras una reunión con el Ministro del Interior Antonio Tróccoli:

"Expresamos [al ministro] nuestro desagrado por los términos empleados por el gobierno que intenta equiparar a nuestros hijos con los represores de estos infamantes años. Señalamos asimismo que no podemos admitir que desde esferas oficiales se diga que las Madres pueden ser manejadas por intereses políticos, cuando nuestra representatividad no es sólo de familias afectadas sino la expresión de un pueblo denigrado por las FF.AA.". ("Comunicado de prensa", Buenos Aires 1 de marzo de 1984). ${ }^{31}$

Consecuentemente, ello hacía que el objeto democracia se convirtiera, como en el discurso de Alfonsín, en una conquista a defender a toda costa. La diferencia radicaba en que en el discurso de Alfonsín ese objetivo subyacente permitía considerar una ética de la responsabilidad política que se antepusiera a una idea de lo justo "a la kantiana" (contradicción entendida entre un imperativo ético para la actuación irrestricta de la Justicia y el equilibrio político inestable de la transición que desalentaba ese juzgamiento in extenso a los militares). ${ }^{32}$ Por su parte, la ética política de Madres se construía en cambio sobre la consideración de que preservar ese logro sería imposible mientras "los asesinos siguieran sueltos", ya que nada evitaba que volvieran a interpretar su rol. En el marco de este presupuesto, por

29 En Periódico Madres de Plaza de Mayo núm.7, junio de 1985. 
ejemplo, mientras la Cámara Federal preparaba las audiencias del "Juicio a las Juntas", el ํ 4 del periódico Madres de Plaza Mayo de marzo 1985 llevó su tapa encabezada por un gran título: "Sin castigo, volverán". Era sobre la base de estos distintos sentidos políticos, cada uno de ellos a su manera políticamente propositivo con respecto a aquel objetivo común que excedía a las demandas de justicia en sí, que puede comprenderse el énfasis de Madres sobre la política del gobierno:

"[Alfonsín] tiene el gobierno y los militares tienen el poder. Hay que decirlo por duro que suene: no podemos callarnos y esto no significa estar contra el gobierno o la democracia, sino que las Madres creemos que así ayudamos a Alfonsín a que se pronuncie duramente para que no se repita lo que pasó. Si no se pone en prisión, pero en serio, a los culpables del genocidio cometido durante la dictadura, en tres o cuatro años volveremos a tener la bota encima".33

Así, desde esta mirada, se entendía que la respuesta política debía resultar acorde a la magnitud del problema político suscitado por lo actuado por los militares, es decir, el "genocidio". Mediante esa posición, se asumía que la represión desatada no cuadraba con el diagnóstico trazado por el gobierno a través de la idea de los "dos demonios", ya que la acción de los militares resultaba inconmensurablemente mayor respecto a otras formas previas de violencia social y tenía consecuencias prolongadas en el presente. Pero sobre todo se confrontaba también con el tono celebratorio contenido en el discurso de la "guerra sucia" o "antisubversiva", que los militares y otros grupos sociales sostenían para justificar, política y moralmente, lo actuado.

Un cuarto punto que distanciaba a Madres de la posición de Alfonsín refería al tipo de sujeto judicativo que auditaría el proceso de juzgamiento de los militares. En esta dirección, se opusieron rotundamente al tratamiento de la cuestión por el fuero militar, abogaron por el fuero federal, y promovieron un proyecto de ley para convertir la figura de la desaparición de personas en crimen de lesa humanidad con el objetivo de facilitar el instrumento legal necesario que garantice un tratamiento adecuado de las sanciones penales en la Justicia federal. ${ }^{34}$ Pero además, cabe destacar, los cuestionamientos alcanzaban también a la Justicia común, ya que difícilmente el Poder Judicial vigente lograría convertirse, en la óptica de Madres, en el sujeto con la responsabilidad necesaria para poder llevar esas condenas a la práctica. En este marco, las acciones del organismo frente al proyecto oficial de justicia transicional se comprenden no solo por la dimensión limitada de esa propuesta política, sino también a la luz del escepticismo inicial sobre las posibilidades de juzgamiento efectivo de los crímenes por parte de la Justicia realmente existente, cuya composición mayoritaria tenía por protagonistas a jueces que habían obrado, cuanto menos, con displicencia durante la dictadura.

Los primeros días de julio de 1984, Madres realizó un congreso nacional en Mendoza al que asistieron más de un centenar de personas. Elaboraron durante el

33 Entrevista realizada por el matutino mexicano "Uno más uno", y distribuida por la agencia de noticias francesa AFP; reproducido en Crónica, La Voz y La Nación, 29/03/1984 -aunque La Nación omitió el fragmento donde se utilizaron las palabras "genocidio" y "dictadura".

34 El viernes 4 de mayo de 1984, en conjunto con representantes de otros organismos, marcharon al Congreso de la Nación para solicitar la creación de la figura de la desaparición forzada de personas como crimen de lesa humanidad, y depositaron en la Cámara de Diputados a tal efecto una carpeta que contenía 200.000 firmas con esa petición. Crónica, 5/05/1984. 
encuentro un documento colectivo donde condenaban la existencia de intentos para favorecer "el olvido, la impunidad o la reparación" por las violaciones a los derechos humanos, y denunciaban a los jueces que habían ejercido funciones durante la dictadura y que continuaban en actividad. ${ }^{35}$ Cabe destacar, los miembros de la Corte Suprema y la Cámara Federal conformada como la instancia de alzada al fuero militar entraban por principio en este grupo, que ya había quedado definido entre diciembre de 1983 y febrero de 1984. ${ }^{36}$ Aunque Hebe de Bonafini aclararía posteriormente que se referían a aquellos que no recibieron los hábeas corpus o recursos de amparo vinculados a las violaciones a los derechos humanos, ${ }^{37}$ lo cierto es que el colectivo del Poder Judicial aparecía representado como "los principales cómplices" con la política de desaparición de personas. A continuación reiteraron que rechazaban "la imposición de tribunales militares para juzgar crímenes de lesa humanidad que denigran la Constitución Nacional" y reclamaban la "aparición con vida de todos los detenidos desaparecidos" y "si así no fuera, juicio y castigo a los responsables como inicio de una justicia ejemplarizadora". ${ }^{38}$ Bajo esta consigna, Madres promovería, paralelamente al itinerario legislativo y judicial del proyecto impulsado por el gobierno nacional, el desarrollo de otras causas judiciales en distintos estrados, tal como la querella presentada en el primer aniversario en democracia del golpe de estado contra Videla, Massera, Agosti, Harguindeguy y Camps por la desaparición de catorce personas. ${ }^{39}$

Un último núcleo temático que pautó el desencuentro entre las expectativas de Madres y la política llevada a cabo por Alfonsín refiere a la cuestión de los tiempos. Madres consideraba que en la celeridad de los plazos para dar inicio a las primeras medidas judiciales radicaban mayormente las posibilidades de que dichos juicios fueran finalmente posibles, se preservaran las pruebas remanentes de los crímenes y se salvaguardara a los desaparecidos que todavía pudieran encontrarse en campos clandestinos de detención. En ese contexto, además de interpretarse como un medio para la inacción penal, la actuación del Consejo Supremo de las Fuerzas Armadas se veía como un mecanismo de dilación. Por contrapartida, Alfonsín consideró en junio de 1984, durante su visita oficial a España, que el camino de la justicia sería largo ya que se realizaría con la "prudencia política" necesaria para cumplir con ese cometido de acuerdo al "debido proceso". El ex presidente añadía que "esa prudencia es absolutamente necesaria" porque "éste es el tiempo de la justicia democrática y no de los juicios sumarísimos de regímenes totalitarios". ${ }^{40}$ La cuestión de los tiempos en la política radical, que en realidad ya había sido considerada como problema durante el período de redacción del programa de Justicia y que sería retomada en otras ocasiones entre las cuales la ley de "Punto Final" constituye uno de los ejemplos más claros-, ${ }^{41}$ se mostraba todavía abierta al juego político y carecía aún de una definición concluyente, transformando los juzgamientos en un evento que atravesó la agenda pública durante el mandato radical.

35 En Mendoza, 2/07/1984

36 cf. ELIASCHEV, Pepe Los hombres del juicio, Editorial Sudamericana, Buenos Aires, 2011.

37 En Clarín, 3/07/1984.

38 En Mendoza, cit.

39 Clarín, 28/03/1984. En esa ocasión, de Bonafini afirmó que continuarían con la política de presentaciones judiciales.

40 Mensaje de Raúl Alfonsín ante el parlamento español, en Clarín, 13/06/1984.

41 Véase el debate parlamentario de la Ley 23492/86 de Extinción de la Acción Penal -"Punto Final"[en línea] http://www1.hcdn.gov.ar/dependencias/dip/adebates.htm 


\section{Las marchas de las Madres (en La Rosada)}

A pesar de estas y otras diferencias, cabe destacar que Madres procuró reiteradamente acercar posiciones con el Presidente.

A comienzos de marzo de 1984, como se indicó, se entrevistaron con el Ministro del Interior Antonio Tróccoli. A pesar de los exabruptos del Ministro, manifestaron que les aseguró que "los responsables de estos hechos aberrantes irán a la cárcel de por vida" y que todo lo conversado iba a ser transmitido a esa misma noche al Presidente. El 4 de mayo, antes de marchar al Congreso para solicitar la creación de la figura de la desaparición forzada de personas como crimen de lesa humanidad, intentaron colegir dicha petición en la Casa Rosada, pero -según el gobierno dio a trascender, por una dubitación inicial de los cuadros administrativos que no pudo posteriormente ser subsanada- finalmente no fue recibida. El 12 de junio de 1984, un día antes de la alocución de Alfonsín ante el cuerpo legislativo español, un grupo de integrantes de Madres abordó al presidente de imprevisto para reclamar sobre el esclarecimiento de las desapariciones. Alfonsín se comprometió a recibirlas en el Palacio de El Pardo, donde se encontraba hospedado, "para escucharlas sobre todo lo que sea necesario", reunión que se realizó por la tarde del día siguiente. Ya con Alfonsín en Buenos Aires, el 24 de junio realizaron una vigilia de veinte horas en los salones de la Casa Rosada, a la espera de ser atendidas por el Presidente, encuentro que no se concretó. 42

La reunión definitoria entre el organismo y el Presidente se realizó en la casa de gobierno el 6 de agosto, con presencia de Carlos Nino, Jaime Malamud Goti (principales asesores presidenciales en materia de justicia transicional) y Horacio Ravenna (Director de Derechos Humanos de Cancillería -la Subsecretaría de derechos humanos, que asumiría Eduardo Rabossi, se crearía recién tras la entrega en septiembre del informe de la CONADEP-). Asistieron por Madres de Plaza de Mayo su presidenta Hebe de Bonafini, María Adela Antokoletz. María del Rosario Cerruti, Juana Meller, Nora Cortiñas, Carmen Lapacó y Beatriz Aicardi de Neuhaus (quien también integraba Abuelas de Plaza de Mayo). En el encuentro, de acuerdo a la minuta oficial que fue distribuida a la prensa, Alfonsín les manifestó su "claro designio" sobre la necesidad de esclarecimiento y juzgamiento del "doloroso drama de los desaparecidos", aunque señaló en forma tajante la "inclaudicable convicción" de que el "respeto al orden constitucional y al estado de derecho", así como al "principio republicano de la división de poderes", hacían "imposibles las medidas reclamadas por [Madres]". ${ }^{43}$ Finalmente, la comunicación presidencial reiteró se persistiría en cambio en los puntos esenciales ya asumidos por el gobierno (la distinción entre tres grados de responsabilidad para el impulso de los juzgamientos, la primera instancia en los tribunales militares y la justicia federal como instancia de apelación, a la vez que el comunicado reivindicaba la nueva estructura de cargos formulada en los juzgados penales federales donde dicha apelación debería realizarse, así la creación y las actividades de la CONADEP).

El encuentro fue recibido por el organismo como un balde de agua fría, ante la evidente obviedad de que no habían obtenido del encuentro ninguna novedad respecto a

42 "Comunicado de prensa" de Madres, cit; Crónica, 5/05/1984; Tiempo Argentino, 13 y 14/06/1984; Periódico Madres de Plaza de Mayo, núm. 8, julio 1985.

43 La Voz y La Razón 6a. edición, 6/08/1984; Diario Popular, La Prensa, Crónica, La Voz y La Nación, del 7/08/1984. 
las iniciativas que, por motu proprio, el gobierno había vuelto de conocimiento público en diciembre del año anterior; y se fueron, en consecuencia, con las manos vacías:

"Para nosotras es hoy el día más triste, diríamos hasta dramático, desde que se instaló el gobierno del Presidente Alfonsín [...] Podemos decir que el Doctor Alfonsín nos quitó toda esperanza de que su gobierno cumpla lo prometido en cuanto a los derechos humanos, que se mostró como entusiasta defensor de los militares y que, a partir de hoy, las Madres ya no podemos confiar para nada en el gobierno". 44

En ese momento, el organismo contrastó la reunión con la que habían tenido en noviembre del año anterior en el Hotel Panamericano, donde Alfonsín sostuvo varios de sus encuentros claves, antes que asumiera la Presidencia de la Nación. En aquel encuentro -considerado entonces muy positivo-, si bien tuvieron la confirmación de que sería distinto el horizonte judicial que cada parte propugnaría, el presidente electo les había comunicado que "si fuese necesario, iría personalmente a las cárceles" para esclarecer las desapariciones e incluso liberar a quienes todavía pudieran encontrarse con vida, al mismo tiempo que dejaría en "libertad de acción a los legisladores" de su color político respecto a la iniciativa de Madres para la creación de una comisión investigadora bicameral. ${ }^{45}$ Habían considerado entonces que existía un clima de "real solidaridad" con la causa de Madres, y enfatizaron la "sensibilidad" del próximo presidente con esa lucha. ${ }^{46}$

\section{EI Juicio a las Juntas}

En el marco de esas confrontaciones se comprende la posición de múltiples y complejas aristas que el organismo asumió frente al "Juicio a las Juntas". Así, por ejemplo, que el 21 de marzo de 1985 hayan marchado para repudiar la "amnistía encubierta" promovida por la política judicial, y un mes más tarde, el día de inicio de las audiencias, marcharan para manifestar su apoyo a la Cámara Federal. Finalmente, un nuevo distanciamiento se produciría al conocerse las sentencias del tribunal.

Por un lado, a lo largo de 1985 (las audiencias orales y públicas comenzaron el 22 de abril conociéndose la sentencia de la Cámara el 9 de diciembre de ese año) se produjeron múltiples intervenciones públicas de los miembros del gabinete nacional, que brindaron señales cruzadas y contradictorias sobre la trayectoria de la política oficial en materia de derechos humanos. Estas distintas intervenciones (que incluyeron a los Ministros de Defensa, Raúl Borrás y Roque Carranza, al Subsecretario de Derechos Humanos, Eduardo Rabossi, al Ministro del Interior, Antonio Tróccoli; al Comandante en Jefe del Ejército designado por Alfonsín, Ríos Ereñú; al Secretario General de la Presidencia, Germán López; y al Ministro de Justicia, Alconada Aramburú), conllevaron nuevas cavilaciones en Madres y en otros actores del movimiento de derechos humanos acerca de la convicción con la que el Poder Ejecutivo impulsaría o convalidaría nuevos juzgamientos. ${ }^{47}$ En ese marco, la denuncia y las sospechas sobre la existencia de una

44 La Voz, 7/08/1984, entrevista a Hebe de Bonafini.

45 GORINI, Ulises La rebelión..., cit., p. 642.

46 Boletín Informativo Madres de Plaza de Mayo, Año I, núm. 12, diciembre 1983; La Razón 6ta. edición, 23/11/ 1983; Crónica y Nueva Presencia, 25/11/1983.

47 GALANTE, Diego "El Juicio a las Juntas en la escena política argentina", en Revista Lucha Armada en la Argentina, anuario 2014. 
amnistía en curso por parte del gobierno nacional se convirtió, junto al impulso del "juicio y castigo a todos los culpables", en el tema central del medio de comunicación oficial de Madres a lo largo del año, y estuvo presente también en la mayoría de alocuciones públicas de sus representantes.

El 21 de marzo de 1985, mientras la Cámara Federal resolvía las condiciones de instrumentación del juicio oral, las Madres junto a los restantes siete principales organismos de derechos humanos (Abuelas de Plaza de Mayo, APDH, SERPAJ, MEDH, CELS, Liga Argentina por los Derechos del Hombre y Familiares de Detenidos y Desaparecidos por Razones Políticas), organizaron una movilización desde el Congreso de la Nación hasta Plaza de Mayo. La marcha, encabezada por Madres de Plaza de Mayo y conocida como "Marcha de las manos", ${ }^{48}$ fue acompañada además por la Juventud Peronista y la Juventud Radical, el Partido Intransigente y la democracia cristiana, y los principales partidos de la izquierda local. El acto en Plaza de Mayo contó la alocución final de la presidenta del organismo, quien denunció allí una "justicia que de tan lenta y tan corrupta se convierte en injusticia", e interpeló a la clase gobernante para "cumplan con lo que prometen", señalando como el eje de esa demanda, junto a la recuperación de consignas históricas como la de "aparición con vida" y otras más actuales como las referidas a la libertad de los presos políticos remanentes de la dictadura, el "juicio y castigo a los culpables". ${ }^{49}$

Tras la movilización, el intelectual Osvaldo Bayer publicó una nota en la revista de actualidad política El Periodista. Su título fue: "Baje a la Plaza de Mayo, Señor Presidente". Expresaba allí:
“A la Argentina la conocían en el exterior por el fútbol, el tango y la carne. Hoy la conocen por las Madres de Plaza de Mayo [...] El Presidente debe tener un gesto democrático: bajar a la Plaza de Mayo, saludarlas y pedirles disculpas [...] Tengamos en cuenta que las Madres son para las generaciones futuras, el único valor ético, las únicas exponentes de la resistencia del total de un pueblo que no supo exponerse a la dictadura más criminal y corrupta de toda su historia". 50

Alfonsín clausuró en julio de 1985 las internas y discusiones que habían sido promovidas públicamente por su gabinete en el primer semestre del año. En una entrevista grabada para un canal de televisión alemán que fue recogida por los medios locales a través de la agencia EFE, Alfonsín negó el proyecto de la amnistía: "Por el contrario, queremos que los procesos avancen, que actúen los tribunales militares y luego las instancias de apelación". Dos días más tarde, las palabras del Presidente fueron retomadas y explayadas por el Ministro de Justicia Alconada Aramburú, a efectos de potenciar la credibilidad pública sobre esa convicción. Sin embargo, aquella esa misma entrevista, Alfonsín se refirió también a la relación del gobierno con Madres de Plaza de Mayo, y señaló que existían serias diferencias ya que sus posiciones

\footnotetext{
48 La movilización llevó el lema "dele una mano a los desaparecidos" y contó con pancartas con bocetos moldeados de manos enviados desde 68 países. De acuerdo a la agencia Diarios y Noticias congregó a unas 25.000 personas.

49 Crónica y La Gaceta de Hoy, 22/03/1985.

50 En El Periodista, 29/03/1985.
} 
políticas no coincidían: "Yo considero que tienen derecho legítimo a actuar así, pero esto tiene consecuencias negativas para la democracia". De ese modo, Alfonsín retomaba la afirmación expresada en diciembre del año anterior, cuando indicó que Madres de Plaza de Mayo tenía "un objetivo político que no coincide con los intereses nacionales". Con ello daba a entender, finalmente, que eran insalvables las distancias entre la propuesta oficial para el tratamiento judicial del pasado y la que era promovida por Madres, ya en materia de la cantidad de procesos penales, las estrategias más adecuadas para promoverlos, o las consecuencias políticas para la consolidación de la democracia que, según cada sector proponía, se buscaban obtener y evitar a partir de esos distintos proyectos de juzgamientos..$^{51}$

A pesar de los resquemores de Madres sobre la predisposición real del gobierno y la Justicia, fueron protagonistas en la movilización de apoyo al "Juicio a las Juntas" llevada a cabo en la tarde del 22 de abril, cuyo acto central (ante la veda del Ejecutivo a realizarlo frente al Palacio de Tribunales) se llevó a cabo frente al Congreso de la Nación. En la alocución final, cuya lectura estuvo a cargo del Premio Nobel de la Paz Adolfo Pérez Esquivel (SERPAJ) y Monseñor Pagura (MEDH), se expresó el objetivo común de "apoyar el juzgamiento del terrorismo de Estado a través del proceso a sus principales responsables", a partir del cual "la comunidad democrática asume con valor su deber de procurar el triunfo de la verdad y la justicia". De cierto modo, se construía así un espaldarazo colectivo al proceso penal a partir de una transferencia de la legitimidad ganada por el movimiento de derechos humanos durante la dictadura y los primeros años de democracia.

Ese mismo día, al comenzar las audiencias orales, Hebe de Bonafini se ubicó en la primera fila de la sala, junto a Pérez Esquivel, Emilio Mignone del CELS, María Chorobik de Mariani de Abuelas de Plaza de Mayo, y Jorge Taiana por APDH, entre otros. Fueron acompañados, también, por Augusto Conte y Carlos Auyero de la Democracia Cristiana, por los tres diputados radicales que integraron la CONADEP (Santiago López, Horacio Huarte y Hugo Piucill), y por el Subsecretario de Derechos Humanos Eduardo Rabossi y el Director de Derechos Humanos de Cancillería Horacio Ravenna, lo que propiciaba la idea de un punto de encuentro alcanzado finalmente entre el oficialismo y los organismos. Sin embargo, dejaron en claro al mismo tiempo que esa legitimidad no era transferida al costo del abandono de las consignas básicas del movimiento referidas a la profundización de la investigación penal, aspecto remarcado a través la variación instrumentada para la consigna, ya histórica, que acompañó esta vez la convocatoria a la movilización: "Juicio y castigo a las Juntas Militares, y a todos los culpables". Esta dualidad era percibida también en Madres. Dos días antes de la marcha, Hebe de Bonafini había afirmado en la ciudad de La Plata que "el poder judicial está sometido al poder militar, y por lo tanto, está subordinado a sus intereses" ya que "los jueces han jurado para la injusticia", al referirse a la causa judicial. Sin embargo,

51 Las declaraciones de Alfonsín de julio de 1985, en Clarín, 7/07/1985, y la interpretación de Alconada, en "Alconada: La Voz 9/07/1985. Sobre las declaraciones de Alfonsín en la víspera de navidad de 1984 y la respuesta de Madres, Clarín, 3/01/1985. 
durante la primera semana de audiencias, consultada por la prensa, la presidenta de Madres manifestó que "hasta el momento, el juicio va muy bien". ${ }^{52}$

Dicho acompañamiento al proceso penal, aunque con algunas tensiones, se sostuvo hasta la finalización del juicio oral. El momento de la sentencia, sin embargo, fue netamente de ruptura. Al escucharse en la sala la segunda de las cuatro absoluciones, ${ }^{53}$ Hebe de Bonafini se colocó el pañuelo distintivo de Madres, el que se había quitado por pedido expreso del tribunal antes de comenzar la audiencia final. El juez Arslanian interrumpió entonces la lectura de la sentencia para solicitarle que se lo quite, o bien, se retirase de la sala. La presidenta de Madres escogió esto último. La escena, recogida en las crónicas por múltiples medios de prensa, construía así un relato de final circular, que simbolizaba la cesión de legitimidad que Madres concedió al tribunal el día de inicio del juicio oral, y que volvía a reclamar para sí tras la desilusión de la sentencia. El suceso reproducía una igual que se había dado el primer día de las audiencias, momento en que Bonafini había acatado la orden del tribunal. ${ }^{54}$

Ese mismo día, se refirieron con dureza al fallo de la Cámara Federal ante los medios locales. Unos días más tarde, en una entrevista emitida por Radio Mitre con la periodista y ex integrante de la CONADEP Magdalena Ruiz Guiñazú, Hebe de Bonafini deploró que "esta impunidad de hoy es un camino abierto para que se vuelva a reprimir", y señaló que el fallo confirmaba las sospechas iniciales de Madres sobre la política radical: "para nosotras, el fallo no fue demasiado novedoso, porque veníamos anunciando que iba a haber una especie de amnistía encubierta, que no había decisión política para condenar". La desazón en estas afirmaciones era tanto más significativa por cuanto Nora Cortiñas había manifestado, un día antes de conocerse la sentencia, que se mostrarían relativamente satisfechas -si bien esperaban además el juzgamiento de los "1500 militares que fueron nombrados en las denuncias a la CONADEP y ahora durante el juicio"- con una condena "tan rígida como la que pidió el fiscal Strassera" (es decir,

52 Sobre la manifestación de apoyo del 22 de abril (de acuerdo a la agencia Diarios y Noticias, concurrieron 50.000 personas, según a la agencia Noticias Argentinas unas 30.000, y los organizadores contabilizaron unas 100.000), Clarín, 4 y 23/04/1985, Tiempo Argentino, La Razón, Crónica, y La Gaceta de Hoy, 23/04/1985. La marcha, paradójicamente, generó una nueva polémica con Tróccoli, quien restringió severamente la concentración en Plaza Lavalle, frente a Tribunales, donde los organizadores habían programado realizar originariamente el acto. Consecuentemente, la movilización transitó por la Avenida Corrientes, pasó a una cuadra de la sede del tribunal, y se dirigió al Congreso. Diario Popular, 22/04/1985, Crónica 23/04/1985. Los dichos de Hebe en la ciudad de La Plata y tras comenzar el juicio, en Crónica, 21/041985, y Clarín, 27/04/1985. Sobre el lugar destacado en la sala de los organismos, La Razón y Crónica, 23/04/1985.

53 La sentencia condenó a Videla y Massera, a cadena perpetua. Viola fue sentenciado a 17 años de prisión, Lambruschini recibió 8 años de condena y Agosti 4 años y medio. Galtieri, Graffigna, Anaya y Lami Dozo resultaron absueltos. Véase, entre otros, CIANCAGLINI, Sergio y GRANOVSKY, Martín Nada más que la verdad: el Juicio a las Juntas, Planeta, Buenos Aires, 1995.

54 GALANTE, Diego "El Juicio...", cit., p. 104. 
cinco cadenas perpetuas y penas de entre 10 y 15 años de prisión para los cuatro acusados restantes). 55

El número de enero de 1986 del periódico del organismo, destinado a presentar la evaluación del juicio, plantaría esas interpretaciones en forma rotunda. $\mathrm{Su}$ tapa completa estaba ocupada a fondo negro con la ilustración de nueve pañuelos de madres -contratara de los nueve ex comandantes del juicio- que rodeaban a un birrete de oficial ubicado en un banquillo, lo que propiciaba la idea de una acusación renovada y sostenida. ${ }^{56}$ El título era "LA SENTENCIA abrió paso a LA AMNISTÍA", donde los términos del oxímoron, resaltados en un furioso color rojo de alerta, invitaban a asociar esas ideas, bajo un juego de espejos, en una sola. Fue la primera vez que la tapa se imprimió a dos colores, algo que tampoco ocurría en los números siguientes, lo que subrayaba la voluntad de construcción de esos sentidos de forma taxativa. La nota editorial de ese número explayaba: "vamos hilando fino la trama de la negociación que se pone al descubierto [...] no pueden convencernos que se está haciendo todo lo posible para evitar males mayores [...] Ya nadie puede engañarnos ni podrá impedir que, aunque muy penosa, nuestra marcha hacia la justicia continúe". ${ }^{57}$ De ese modo, se postulaba que no habría nuevas cavilaciones en la posición oficial del organismo con respecto a la evaluación del proyecto oficial de justicia transicional. La sentencia del "Juicio a las Juntas", eje de ese programa, era interpretada como el índice de un programa político para clausurar el pasado y un simulacro de justicia. Se convertía para Madres, finalmente, a diferencia de lecturas que primaron en otros y heterogéneos campos de representación social, en el símbolo y el inicio de la impunidad en democracia. Las leyes de "Punto Final" y "Obediencia Debida" en 1986 y 1987, así como posteriormente los indultos en la era menemista, serían interpretadas como una confirmación de esa lectura.

A pesar de ello, ese mismo recorrido y las posiciones asumidas en los primeros años de democracia impactarían al interior de Madres. Entre enero y abril de 1986, se volvieron públicas disidencias latentes respecto a la estrategia de lucha del organismo, diferencias que se habían ido forjando también, entre otros aspectos, al calor de las iniciativas del gobierno nacional para el tratamiento del pasado, y la actitud de distanciamiento o apoyo con que distintos grupos de Madres entendían que cabía acompañar aquellas que podían considerar, en términos relativos, un avance. Estos conflictos derivaron en la creación de la "Línea Fundadora" el 10 de abril de ese año. Se expresarían también, aunque posteriormente, en la adopción de algunas estrategias

55 Estas valoraciones distinguían a Madres, además, de las que primaron en otros organismos. Si bien la carga de las penas y las absoluciones se convirtieron en un cuestionamiento común, el hecho de que el juicio se haya consumado y las perspectivas abiertas por el "Punto 30" del fallo de la Cámara (donde se solicitaba la investigación penal de los perpetradores materiales de los crímenes probados a los ex comandantes), fueron recibidos -con distintos énfasis y matices- como un resultado alentador en el resto del movimiento de derechos humanos. Sobre la recepción de la sentencia en Madres, Clarín, 10/12/1985, y El Diario del Juicio, 11/12/1985. Las declaraciones de Hebe de Bonafini durante el programa de Ruiz Guiñazú, en La Nación, 3/011986; y las expectativas previas de Cortiñas, en La Razón, 9/12/1985.

56 La imagen ya era utilizada, aunque con un rol secundario, acompañando el título del periódico desde su primer número en diciembre de 1984, y se encontró repetida junto a los créditos y bajo la editorial del periódico en el volumen de enero de 1985, tras que la Cámara Federal decidió asumir el expediente que estaba siendo tramitado en el Consejo Supremo de las Fuerzas Armadas.

57 Periódico Madres de Plaza de Mayo, núm. 14, enero de 1986. 
diferenciales de conmemoración del terrorismo de estado. Sin embargo, los puntos básicos del desencuentro entre las Madres y Alfonsín -la judicialización limitada de los crímenes, el dislate en los tiempos de la Justicia o la indulgencia de sus fallos, la exclusión del cuerpo parlamentario como sujeto del proyecto transicional, y la criminalización de las víctimas del terrorismo de estado- fueron preservados como enunciados comunes en las dos líneas internas. ${ }^{58}$

\section{Conclusiones}

El recorrido propuesto permite ilustrar la serie de desencuentros entre el gobierno de Alfonsín y Madres de Plaza de Mayo durante la transición a la democracia en Argentina. Iniciadas en diciembre de 1983, esas discusiones tuvieron su momento más álgido de intercambio político en agosto de 1984, aunque se consolidaron como una ruptura decisiva tras conocerse el fallo del "Juicio a las Juntas", en diciembre de 1985. Dichas diferencias se construyeron en base a múltiples dimensiones, de distinto tenor. Involucraron elementos jurídicos y otros relativos a la instrumentación de los procesos penales (el alcance de la acción penal a los perpetradores directos, la actuación en primera instancia del fuero militar y la celeridad de la acción judicial, la distribución de las penas); otros aspectos que discutieron la construcción de la política y de lo político que impulsaba cada una de esas iniciativas en disputa (la participación del parlamento en la investigación de los crímenes cometidos en dictadura, las consecuencias para la democracia que cada grupo suponía en una política demasiado blanda o demasiado dura de juzgamientos); y otros elementos que se orientaron a confrontar las posiciones culturales en la interpretación de ese pasado traumático y sus consecuencias en el presente (la "teoría de los dos demonios", la política social y económica regresiva de la represión). A pesar de esas diferencias, plasmadas en múltiples campos de representación y acción social, los primeros años de la transición se mostraron como un proceso en el que, en distintas oportunidades, esas perspectivas diferentes procuraron ser aproximadas. El momento concebido como clave de esa transición en el proyecto oficial (el proceso penal a los ex comandantes de las Juntas), y las evaluaciones contrapuestas que se construyeron sobre él, pautaron en buena medida que esas estrategias de aproximación se volvieran finalmente posiciones irreconciliables.

Opacados por otros conflictos que sí incidieron, aunque con distintos grados, en la frágil estabilidad política de la transición (con los militares, las corporaciones y crisis económicas, el diálogo con el peronismo y la cuestión sindical, entre otros), ${ }^{59}$ los desencuentros del Poder Ejecutivo con Madres ocuparon en la historiografía un rol más bien secundario en la historia política de los ochenta. Sin embargo, resultan claves para comprender los intersticios de la lucha por los derechos humanos y contra la impunidad en Argentina, así como las características centrales de su expresión en los primeros años de democracia.

Pero también, esas posiciones y los conflictos durante el gobierno de Alfonsín pueden contribuir a echar luz sobre otros procesos posteriores. En este marco, puede

58 GORINI, Ulises, La otra..., cit., pp. 521-530 y 551-562; BOSCO, Fernando "Human Rights Politics and Scaled Performances of Memory: Conflicts among the Madres de Plaza de Mayo in Argentina", en Social and Cultural Geography, Vol. 5, Issue 3, 2004, pp. 381-402.

59 NUN, José y PORTANTIERO, Juan Carlos (comps.) Ensayos sobre la transición democrática en Argentina, Puntosur, Buenos Aires, 1987; PUCCIARELLI, Alfredo (coord.) Los años de Alfonsín: ¿el poder de la democracia o la democracia del poder?, Siglo XXI, Buenos Aires, 2006. 
pensarse por ejemplo que el renovado protagonismo social de las Madres desde el llamado "boom" de la memoria de la segunda mitad de los noventa, a partir del cual se consolidaron las denuncias públicas de las iniquidades sociales presentes como contracara del proyecto neoliberal iniciado en dictadura y su impunidad durante la transición, su influencia en las nuevas generaciones del movimiento de derechos humanos, y la proximidad con el gobierno de Néstor Kirchner en el nuevo siglo -al interpretar la existencia de un correlato programático y sentimental con las consignas sostenidas en los ochenta ${ }^{60}$, fueron resultado de la lucha y de la impronta que se consolidó en la transición. Es decir, los desencuentros con aquel gobierno -expresados bajo la forma de políticas punitivas concretas pero también sobre las formas de profundizar la naciente democracia- al que se reclamaba al mismo tiempo "juicio y castigo a todos los culpables" -como reparación histórica y justicia ejemplarizadora- y se le endilgaba su política económica -en la que se entendía el mismo grado de timidez frente al poder saliente- como la "otra cara de la injusticia". ${ }^{61}$

Buenos Aires, mayo de 2017.

60 Cf. LORENZ, Federico “¿De quién es el 24 de Marzo? Las luchas por la memoria del golpe de 1976”, en JELIN, ELIZABETH (comp.) Las conmemoraciones: las disputas en las fechas in-felices, Siglo XXI, Madrid, 2002; BONALDI, Pablo "Hijos de desaparecidos, entre la construcción de la política y la construcción de la memoria”, en JELIN, Elizabeth y SEMPOL, Diego (eds.) El pasado en el futuro: los movimientos juveniles, Siglo XXI, Madrid, 2006; ANDRIOTTI ROMANIN, Enrique “CCooptación, oportunidades políticas y sentimientos? Las Madres de Plaza de Mayo y el gobierno de Néstor Kirchner”, en Polis, vol. 13, núm. 39, 2014, pp. 1-13.

61 La tapa del Periódico Madres de Plaza de Mayo núm. 17, correspondiente a abril de 1986, llevó por noticia central la denuncia del modelo económico de Alfonsín. El titular proponía: "Salarios de hambre, desocupación, privatizaciones, mayor dependencia. Plan Austral: otra cara de la injusticia". 